Journal Home Page:

http://perlinguam.journals.ac.za
Per Linguam

A Journal for Language Learning Tydskrif vir Taalaanleer

\title{
CONVERSATION PRINCIPLES AND SECOND LANGUAGE UTTERANCES
}

\author{
Phyllis Kaburise \\ University of Venda
}

Conversation principles, such as those of Grice (1957, 1968, 1975), Austin (1962), Searle (1962, 1969) are formulated to enable interlocutors to interact meaningfully, in a linguistic project. Non-observance and flouting of these principles occur regularly in the verbal behaviours of users of a language, indeed, sophisticated users of a language, sometimes deliberately go against these norms, as stylistic devices in their output. When such non-conformities occur, hearers and readers resort to implicatures, maxims, inferences and their general world knowledge to interpret an utterance. Although the decision to observe some, and not all of the principles during a linguistic encounter, may seem to be taken casually, it is the contention of this paper that such decisions are made deliberately, particularly, by users of a second language. This paper attempts to identify the selection processes involved in the creation of some utterances produced by Ghanaian and Tshivenda second language users of English, using Grice's verbal interaction maxims. The discussion will focus on the tension between semantic and pragmatic meaning, the factors involved in the creation of linguistic meaning and the role that interaction requirements such as Grice's conversational maxims and the concept of a New Englishes approach to language play in the creation of some second language utterances.

\section{Keywords}

Grice's conversation maxims, implicatures, pragmatics, flouting of conversation principles, New Englishes

\section{INTRODUCTION}

That the main objective of any language is to communicate the wishes of its users hardly needs any elaboration. The communication process involves complex verbal behaviour where the participants have to accommodate a variety of interconnected factors before meaning can be generated. The principal meaning-generating tool of humans is their ability to signal their linguistic system or language. This linguistic system can be exploited for the purposes of communication if the speakers are able to succeed in making hearers aware of something (thoughts, opinions, facts, emotions and so on) which they were not aware of previously. Successful communication depends not only on the receivers' reception of the message and their appreciation of the fact that it is intended for them, but also upon hearers' recognising the 
senders' communicative intent and making an appropriate behavioural or linguistic response to it. However, it would be fallacious to assume that if one can speak, then one can communicate. In this paper, communication is viewed as behaviour dependent on multiple variables such as the nature of the language used, the nature of the interlocutors and the context of the utterance. All of these variables must be factored into meaningful analysis.

It is widely agreed that second language (L2) users bring their old thought processes to the creation of linguistic meaning in the new language. The argument is that although on the surface of it, some of the choices they make seem to challenge English norms, in actual fact they follow L2 users' interpretation of some internalised principles and maxims in English, coincidentally or by design. This paper hypothesises that some expressions of L2 users, for example, the Ghanaians and the Tshivenda, which may be considered 'quaint', 'idiosyncratic', 'marked' in English are actually the result of very deliberate selection processes from available alternatives, influenced by these speakers rich linguistic heritage and the observation of pragmatic norms such as Gricean (1975) conversation principles. These expressions are also manifestations of the concept of New Englishes (Platt, Weber and Ho, 1984; Bamgbose, et al. 1995) a concept linked directly to pragmatic study of communication. This analysis will be done by outlining what is meant by a pragmatic competence in language; by discussing Grice's four conversation maxims and showing the relevance of the concept of New Englishes in the analysis of selected utterances from Venda and Ghana.

I hasten to add here that I am not referring to blemished utterances which violate structural and functional norms in English but rather utterances which have been created to satisfy processes, or activities which are peculiar to the producers. In the New English context, Kachru (1992) differentiates between mistakes and deviations. He indicates that mistakes are never justifiable as they do not belong to the norm of the language but deviations are different, as they are results of production process and are deviations from a norm, which in his view, should be flexible.

\section{PRAGMATICS}

Montague (1974: 96) refers to the early beginnings of pragmatics:

It was suggested ... that pragmatics concerns itself with what C.S. Peirce had in the last century called indexical expressions, that is words and sentences of which the reference cannot be determined without knowledge of the context of use....

Pragmatics did not have any formal or precise structure until the fifties when Montague and his others tried to define it Monatague (174: 98). These attempts to define pragmatics as a distinct area in meaning creation were seen as very tentative and uninspiring. To define means to impose boundaries; defining 'pragmatics' therefore, implies determining its frontiers with other adjoining fields of study, within and possibly outside of linguistics. Such definitions of pragmatics were originally quite elusive with authors either confining themselves to a strictly linguistic definition or incorporating so many contextual and societal factors that pragmatics became vague, subjective and hence unwieldy (Leech, 1993). 
Just what constitutes 'pragmatics' has been an open question for a long time, even after Morris (1938: 6) defined it as 'a branch of semiotics' or 'the study of the relation of signs and interpreters'. Today, in less technical and more communicative-orientated terms, one would talk of 'message' and 'language user'. Pragmatics therefore starts out from a basic conception of language as being interactive, or in relation to its 'users'. Mey (1993: 5) underlines the idea of pragmatics being concerned with synchronic usage:

That is to say, not the science of language in its own right, or the science of language as seen and studied by the linguists, or the science of language as an expression of our desires to play schoolmarm, but the science of language as it is used by real, live people, for their own purposes and within their limitations and affordance.

Whereas the aims of syntax and semantics and their place in language study are relatively clear, the task of pragmatics and its contribution to linguistic meaning are not as clear. Pragmatics, once described by Leech (1993:1) as the 'rag-bag' of language studies is now respected as a study which enables us to understand the nature and structure of language and the way language is used in actual communication. It draws its inspiration mainly from the philosophy of language, as it is an attempt to investigate the nature of meaning creation using natural language. It is an attempt to unravel the process involved when speakers and hearers encode and decode language. It is this aim which ensures a central place in pragmatics for conversation principles.

Although discussions on pragmatics testify to the variety of phenomena studied under the guise of pragmatics, most of them view pragmatics as an account of the interrelations between language and the communication situation in which it is typically used. Running through literature on pragmatics is the notion of 'action' or language as a 'tool' to be used in a real world, one of the reasons usually cited for the development of pragmatics. Perhaps one of the most pertinent reasons for the development of modern pragmatics was the growing irritation with the lack of overt interest, among established linguists, for example, Chomsky (1957), in what really goes on in language: in what people actually 'do with words'. Among those who took this concern seriously was Austin, who, in 1962, wrote his classic work on pragmatics, How to do things with words. As Mey (1993: 23) says:

The title of Austin's book contains an explicit question, the answer to which is not, of course, that people should form correct sentences or compose logically valid utterances, but that they communicate with each other (and themselves) by means of language ... as knowledge of the syntax, phonology and semantics of various languages has increased, it has become clear that there are specific phenomena that can only naturally be described by recourse to contextual concepts.

One of the factors, therefore, which has been instrumental in the elevation of pragmatic meaning, is the renewed interest in the users of the language in the real world, as compared to language as a system, or language in the abstract. The 'users' of language in the 'real world' are, for pragmatics, the very condition of its existence. Once the notions of 'users' and 'real world' become part of the scenario we can refer to pragmatics as the study of 'contextualised meaning'. That is: 
(A study) in which the users are the paramount features of interest, inasmuch as they are the primi motores of the entire linguistic enterprise, both in its theoretical and its practical (usage-bound) aspect... (Mey, 1993: 31).

In pragmatics, most discussions on contextualised meaning include a differentiation between literal and intended meaning of natural language, whereby 'literal meaning' is identical to the meaning of a sentence without context (semantics) while 'intended meaning' is reserved for meaning achieved after consideration of context, conversation principles and any implications that may exist (pragmatics). Annette Herskovits (1997), writing on pragmatic context, language and meaning, reviews the various types of context which interact with a proposition for communication. She suggests that for a linguistic communication to be successful speakers and hearers need to know the relevant co-ordinates of the pragmatic context. Similarly, ethnographic researchers acknowledge that no serious analysis of language can be carried out without appealing to some kind of pragmatic meaning. This type of meaning is a dynamic area of language study in its attempt to contribute to a comprehensive picture of meaningful communication.

Brown and Yule (1983: 1) also note that

the analysis of discourse is, necessarily, the analysis of language in use. As such, it cannot be restricted to the description of linguistic forms independent of the purpose or function which these forms are designed to serve in human affairs.

This suggests that an analysis of language output cannot be independent of its purpose and context. Central to this paper, therefore, is an approach to language that acknowledges the instrumentality as well as the autonomy of any language system or analysis (Halliday, 1978: 36). A pragmatic description of language relies on exploring the form and the function of an utterance within a given situation. Although the formal or structural regularities of an utterance may also be examined in such an exercise, a functional interpretation alerts an analyst to the way patterns of talk are put to use in certain purposes, in particular contexts. Pragmatics explains the communicative competence of the users of the language in terms of how they manoeuvre their linguistic competence and their linguistic needs in society.

\section{SENTENCE MEANING AND UTTERANCE MEANING}

Grice (1971: 54), making a similar point to Herskovits (1997) differentiates between semantic and pragmatic meanings. He refers to semantic meaning (sentence meaning) as 'basic' and 'conventional' while pragmatic meaning (utterance meaning) is 'non-conventional' and 'implied' or in his terminology, 'meaning-nn'.

In a series of influential and controversial papers Grice (1957, 1968 and 1969) has argued that the meaning of a word is twofold: token and non-natural (meaning-nn). The former refers to what speakers mean by that word, in individual instances of uttering it (it is also the 'universal type' meaning for such a word) while the non-natural meaning opposes formalist orthodoxy in semantic theory, according to which the universal conventional meaning of a word predetermines what a word would mean in any instance of its use. Grice (1957: 381) holds that what a word 
'means' is derived from what speakers mean by uttering it and further adds that 'what a particular speaker or writer means by a sign on a particular occasion ... may well diverge from the standard meaning of the sign'. That is to say, the critical insight of Grice's meaning-nn is that what the speaker intends to communicate need not be related to conventional meaning at all. Speaker meaning need not be code-related but may be inferred through processes quite different from the encoding and decoding processes assumed by the code model of communication. In other words, an utterance needs not encode one's intentions, as understanding an utterance is not merely a matter of decoding it. This has led to the acceptance that 'sentence meaning' may differ from 'speaker meaning'. That is, a contrast may exist between the strict semantic content of some utterances and what is communicated beyond that. This notion is also referred to as the differences between the 'sense' and the 'force' of an utterance, where the former is seen as the sentence meaning and the latter, the utterance or speaker meaning.

Ruth Kempson (1975) also sees this distinction as the relationship between properties of grammar (sentence meaning) and principles of conversation (speaker meaning). Speaker meaning implies a more social, contextual view and sentence meaning has a more abstract cognitive slant. This distinction is part of the rationale for this paper, since the assumption supporting this analysis is that an utterance can be analysed on its grammatical status but more importantly on the utterance's value as a communication tool. One of the premises in this paper is that a language is primarily for the exchange of ideas and that any evaluation of it should stress its ability to perform that role. Naturally the study does not downplay the more abstract cognitive aspect of language; hence the analysis also pays attention to the codes used to exchange the ideas.

Therefore, in articulating the dichotomy that may exist between sentence and utterance meaning, Grice's framework (1975) does allow speaker meaning to have some freedom from conventional meaning. Grice (ibid) claims that when such freedom is present meaning creation relies, among others, on factors like the interlocutors' a) inferential ability; b) their ability to interpret indirect acts from their knowledge of speech acts; c) their familiarity with general principles of conversation and d) their mutually shared factual information ('encyclopaedic knowledge'). Competent speakers of a language are aware of these factors and interact with hearers accordingly, knowing that hearers - like other competent social beings and language users - will deduce utterance meaning by recognising the implications of what is said or not said. Each of these factors forms the core of a pragmatic examination and analysis of discourse.

\section{INFERENCE AND IMPLICATURE}

As noted above, what we mean is hardly limited to what we explicitly say. Normally, we do not have much difficulty in grasping what a speaker is trying to communicate implicitly. The notion that there is divergence between sentence and speaker meanings or that there is underdetermination in our linguistic behaviour serves as the impetus for Grice to come up with the notions of entailment, presuppositions, implicature and inference which are the ingredients of natural conversation. Grice (1975) believes that a speaker, sometimes, gets the hearer to understand the message by relying, among other factors, on the hearer's capacity to make inferences and implications. 
Originating from the Latin word 'plicare' (to fold), the word 'implication' means that which is 'folded in' and has to be 'unfolded' in order for an utterance to be understood. An utterance can imply a proposition that is not part of the utterance and that does not follow as a necessary consequence of the utterance. An implicature is an inference, or additional message that the hearer is able to work out from what is said by appealing to various cognitive structures. Levinson (1983: 115), for example, says that implicatures are like deductive devices. Bach and Harnish (1979: 92) claim that implicatures 'might be called inference to a plausible explanation'. Speakers convey meaning by implicature while hearers 'infer' meaning from the implicature. Simply put, to imply is to hint, suggest or convey some meaning indirectly by means of language. An implicature is generated intentionally by the speaker and may or may not be understood by the hearer. To infer is to deduce something from evidence (this evidence may be linguistic, paralinguistic, metalinguistic or non-linguistic). An inference is, therefore generated by a hearer. Sperber (1995: 194):

"Inference" is just the psychologists' term for what we ordinarily call "reasoning". Like reasoning, it consists in starting from some initial assumptions and in arriving through a series of steps at some conclusion.

Implication is therefore the basis for the distinction between implicit and explicit meaning. To imply is the act of communicating more than is said.

\section{CONVERSATION PRINCIPLES}

Grice (1989) asserts that in addition to interlocutors relying on implications and inferences, a speaker and hearer respect certain rules which ensure communication takes place even if the intention of a speaker may not have been captured by the physical codes. Linguistic interaction is a co-operative and social enterprise, hence users of the language observe these rules in the process of socialisation. There are many unstated and complex rules of interaction that citizens of the same speech community share and it is assumed that they bring these postulates to any communication encounter.

Grice succinctly calls these postulates, conversation maxims or principles. These are

- Quantity: Make your contributions as informative as is required (for the current purpose of the exchange). Do not make your contribution more informative than is required.

- Quality: Do not say what you believe to be false. Do not say that for which you lack adequate evidence.

- Relation: Be relevant

- Manner: Avoid obscurity of expression. Avoid ambiguity. Be brief. Be orderly. 
In formulating the cooperative principles, Grice (1989: 29) believes that conversation is a form of rational purposive behaviour, the goal of which is 'a maximally effective exchange of information' hence these maxims are not arbitrary but a reasoned or rational way of explaining language users' ability.

Grice (1989) conceives the role of the maxims as yardsticks to determine whether a conversational intervention is suitable or unsuitable in an endeavour that has as its goal, the exchange of information. A suitable move is one that furthers the common goal of an exchange while an unsuitable one does not. Grice (ibid.) argues that the participants in a conversation agree on a purpose or direction. This purpose may change throughout the conversation, yet at each moment there is some mutually recognised direction for the conversation. In Grice's (ibid.) model each participant cooperates in an attempt to achieve that purpose and both speaker and hearer typically assume that utterances are governed by these four maxims. When these maxims are not observed, participants are forced to find alternative ways of arriving at the meaning of an utterance.

Although the articulation of the maxims is seen as one of the major break-throughs in explanation of communication, it has also generated a fair amount of debate. One usual question is whether all the maxims are necessary and whether it is not possible to have one superordinate maxim. Green (1989: 89), for example, mentions her doubts about having two parts to the maxim of quality. She believes that the first part 'Do not say what you believe to be false' logically entails the second part 'Do not say that for which you lack adequate evidence'. She also feels that the parts of the maxim of quantity 'Make your contribution as informative as is required' and 'Do not make your contribution more informative than is required' could be succinctly captured by the third maxim 'Be relevant'. Stephen Neale (1989) wonders why there are no rankings on the individual maxims to assist in cases where it is impossible to observe all of them (or all of them to the same degree). Even though Grice (1975: 27) does acknowledge that observing 'some of these maxims is a matter of less urgency than the observance of others', he is unable to provide 'weightings' which could assist participants to determine the status of their interactions. Other questions raised are: What does it mean that a 'contribution should be as informative as is required'? When precisely does a contribution cease to be relevant? What is the status of the maxims? Are they rules, conventions or, as Sperber and Wilson (1986) claim, just 'empirical generalisations' hence obvious?

These Gricean maxims are, nevertheless, particularly relevant to the discussions which are about to follow. This is because, important to Grecian pragmatics is the notion of speaker meaning. Other types of discourse analysis strategies concentrate on other aspects of conversation. For example, structural analysis examines the grammar constituents that go into creating an interaction, ethnographic analysis places emphasis on the social context governing an interaction while using the speech act theory results in a discussion of speech acts - requests, offers, refusals, etc - within discourse and how they are expressed. Since speaker meaning, the emphasis of Grice's maxims allows for different levels of meaning, such as speaker meaning, literal meaning and hearer meaning, and since this paper examines and evaluates utterances at various levels, these maxims are most appropriate for the exercise at hand. 


\section{NEW ENGLISHES}

New Englishes, a socio-linguistic concept is particularly relevant at this point in the discussion since the concept also deals extensively with speaker meaning and context. This concept is premised on the acceptance that English is an international language spoken in a multitude of countries and in a multitude of situations and contexts. It is the result of speakers that come in contact, individuals who find themselves with the need to communicate with speakers of variant languages. New Englishes is an acknowledgement that users are not trapped in a choice-denying straitjacket; there is freedom within the variables they have to work with. There is creativity. Users create an enabling code, one that would enable them to create relevant meaning within the scope of their linguistic wishes.

Once a language operates in such a context, it acquires certain characteristics, one of which is that it becomes 'localised' and then reflects the flavours of the everyday users' local customs and linguistic practices. In the heyday of colonialism, New Englishes were regarded as substandard English, accorded the same derogatory classification as pidgins and vernacular English. Now with advocates like Platt et al. (1984), Bamgbose (1992), Bokamba (1992), and Kachru (1992) see the phenomenon as a development of the English language in response to its diverse users. New Englishes' creation and development are regarded as dynamic processes which should ultimately lead to an increase in the recognised varieties of English, at par with existing standard varieties. In other words, the world should not be astonished at Englishes like Nigerian English, Ghanaian English, Indian English, Philippine English or South African English.

One characteristic of these varieties of Englishes is the extension of aspects of English like accent, intonation, semantic properties of words, rearranging of ordinary English expressions, style and sentence structure in accordance with local linguistic mannerisms. In a way, these Englishes are attempts by non-native users of English to make the language comfortable, and responsive to various contexts of use and this is what the samples analysed below demonstrate. Certain languages are structurally very rigid, not allowing for organisational latitude while others are only so to a certain degree. English falls in the latter category and this has facilitated the development of New Englishes.

\section{SELECTION PROCESSES INVOLVED IN THE CREATION OF SOME ENGLISH UTTERANCES BY L2 USERS}

With this background, expressions of English L2 users are fertile grounds for pragmatic analysis of communication. The analysis which follows is an acknowledgement that language users create meaning differently in response to the variables that exist in their lives and their understanding of the principles that govern meaning creation.

Let us now look at some English expressions which are typically uttered by Ghanaians and speakers of the Tshivenda language which capture the thought processes, the traditions and activities of these two societies. The utterances I have selected are interesting, for a number of reasons.

For example, utterance 1 below is a perfectly acceptable 'subject + verb + adjunct' combination. The syntactic comment that can be made here is about the lexical item 'outdooring'. Although 
not a word that is usually heard, it exhibits the properties of an ordinary verb. 'Outdooring', the present participle form of the verb is used as a descriptive item for 'ceremony', a function legally performed by most present participle forms of verbs. However, it is an expression which could be frowned upon by some hearers and be said to have broken one or more of Grice's maxims, particularly, quantity and manner. It is very common for Ghanaians to say:

\section{1) You are invited to an outdooring ceremony.}

This is an occasion when a seven-day old baby is taken out to meet the public for the first time. One would ask whether the word 'ceremony' is appropriate in the first place and secondly why the activity is not described using more usual sentence constructions like:

- I have a baby, do come and meet her or him.

- Do come and see my baby.

- People are allowed to meet my baby for the first time, please join us.

The list is endless. If Ghanaians were asked why the rather quaint way of expressing this mundane activity, they would have to give the hearers a social history of Ghana before hearers would agree that no English conversation maxim had been broken. For example, hearers would be told that in a society where formerly belief in witchcraft was rift; where polygamous marriages led to jealousy and strife in the family; where survival rates of new mothers and their new-born babies was low; where potent poisons could be created from an extra handful of leaves into the life-giving quinine brew, then the hearer would appreciate that bringing out a baby, not just any baby, but a living baby for the first time deserves to be called a 'ceremony'. They would also hear that a baby is actually taken out of the darkened interior of the hut, where it has been for a whole week, into the sunlight for the first time. More mundane expressions for this activity would seem woefully inadequate.

The next question then is, if these conditions no longer exist, as most mothers go to hospitals to have their babies and everybody is welcome to visit them, then why retain the expression? The expression is retained because the awe that surrounds birth and death still exist. All this background detail has to be inferred by the hearer of the utterance.

If one goes to Makola market, the central market in Accra, Ghana, before sunset when the traders are packing their wares, a statement one may hear the powerful market ladies saying is:

\section{2) Please don't disturb me, I am reading /looking at, my money.}

This means it is time for serious business, it is time to count money, it is time for the accounts. A hearer not familiar with the concept of market women in West Africa would pause with a look of amusement and make what she or he considers appropriate semantic adjustments to the utterance.

In other words, the hearer would assume that the speaker had broken the maxim of manner by making a statement which has lead to obscurity as a result of the unusual collocating of 'money' with 'reading'. Otherwise the expression is an ordinary complex sentence, which for stylistic effect, the conjunction has been left out. Syntactically the sentence can be rearranged in various ways depending on the desired connector. 
The selection of those semantic items, 'reading or looking' as applied to money in this utterance, is deliberate and very appropriate in the Makola market context. The pioneers of the market were hardworking, no-nonsense women with minimal formal education, but with strong survival instincts. When paper money was introduced and rudiments of numeracy were needed, these women had to devise a strategy to continue exchanging their wares for the correct amount of money.

These women were, and still are, economically and politically extremely powerful hence a need to accommodate them in the market economy. For these women the written amount on the note did not matter, what mattered was the picture on the note and colour of it. Therefore assessment of one's wealth involved a cursory glance at the colour of the note and what was going on in the picture, not at a number in the corner of the note. Indeed it was not unusual to hear prices expressed as 'two dancing girls' or 'five traditionally dressed children'.

Now, although many of these women can claim exposure to formal education, and Ghanaian currency is now in line with international practices, these women retain such expressions. The inference to be drawn is that they are very careful with their money, and do not just glance at it; a tacit warning that they cannot be swindled by their assistants or academically-more-inclined customers. The unwillingness of these women to exploit more conventionally structured utterances is an example of the deliberate flouting of the conversation maxims for particular effect. In fact accomplished users of English exploit this stylistic devise with impunity, daily, as when they use verbal devices like sarcasm, innuendo, irony, euphemisms and so on.

In other words, this choice of utterance structure, by the market women, is a deliberate demonstration of their independence; the assertion of their rudimentary formal education; the boast of survival in the world of the market and a formal-education loving society; and a warning to would-be advantage-takers. Such emotions, such objectives, such messages are not so aptly captured, I believe, by expressions like,

- I am checking my money.

- I am doing my accounts

- I am balancing my books.

The decision to retain this expression despite the change in context is therefore deliberate. What a hearer hears is an utterance which is not devoid of misunderstanding, but has it broken any of the maxims? No, the notions of quality, quantity relevance and manner have been observed.

Interestingly, this expression is quite logical for the speakers because the verb 'to read' also means 'to count' but they choose to exploit the other meaning. In addition, some other African countries, for example, Zambia, also do not make a distinction between the two verbs and the meaning is determined by context clues.

Other culturally-oriented statements one might hear from Ghana are:

3) The enstoolment ceremony will take place this Saturday.

4) We went to an engagement party. 
Utterance 3 is a literal translation of the expression used to describe the installation of a chief. The word 'enstoolment' is description of what actually takes place during the ceremony. Like kings, where the symbol of authority is a throne, in the case of the chiefs in Ghana, the symbol is an ornate stool where the newly installed chief is placed. For those not in the know, the word 'enstoolment' could cause some misunderstanding, therefore implying the breaking of the maxim of manner - avoid obscurity of expression. Such a pronouncement would definitely invite challenge. 'Enstoolment' more graphically describes the actual process more than the less specific and multi-functional word, 'installation'. As noted in the discussion on New Englishes the distinction exhibited by these new varieties at most times is seen in the localisation of native English expressions to increase their usefulness. Alternatives to this construction could be borrowing the Ghanaian word into the English expression or substituting it with its closest English synonym.

The utterance cannot be said to be have any syntactic blemishes as the word 'enstoolment' is functioning as an adjective and the ending '-ment' is a usual adjective ending. A similar point can be made for utterance 4 where the word 'engagement' is normally a noun. An 'engagement party', one can guess is a party to celebrate the engagement of a couple. It can be argued that in this context the word 'party' could be omitted since an engagement is usually celebrated in the form of a party. If the word 'party' is omitted, this will prevent the expression from breaking the maxim of quantity - do not make your contribution more informative than is required. However, one can argue that in Ghana the activities are in two sessions. The first part which is more culturally-oriented and follows fixed traditional practices can not, strictly speaking, be classified as a party hence the need to specify whether the person is attending the first or second session.

Utterance 4 can also be questioned on the semantic grounds that a contradiction is implied in the sentence as the first part might be seen as not accommodating the second part. That is because the word 'engagement' is usually synonymous with 'appointment' and has the connotation of a formal, business type of occasion. But as meaning is created within a context, a narration of the surrounding details answers any semantic misgivings a hearer might have. In this regard an analysis has demonstrated that despite the initial charge of flouting the conversational maxim of quantity, a justification can be offered.

In Venda one hears the English expression:

5) He is my cousin brother.

6) She is my small mother.

7) He is my big father.

Though most people, even those without a South African language background, can, albeit with some difficulty decipher the meaning of utterance 5, semantically it still poses some problems: is he a brother or is he a cousin? Cousin we know is a gender-free lexical item hence the sex of a 'cousin' is inferred from context clues. Thus by Gricean principles the utterance has broken the maxim of quantity: that we should make our contribution only as informative as is required by the current exchange. Here again it is the hearer who will decide whether any unneeded information or details have been offered. For the hearer may want to know the justification for the extra information. Is there some significance to knowing that this is a male cousin? A speaker says 'yes' otherwise she or he would not have structured the utterance in this manner. A speaker 
wants us to have that extra piece of information because it shows her/his thought and selection processes in communicating that piece of information.

What the speaker is saying is that 'that nameless, sexless, faceless nebulous individual' referred to as a 'cousin', in the new language, does not suit his or her way of regarding people. Speakers are saying they want to interact in concrete phenomena, hence a need to team 'cousin' with a word which has definable borders: brother. In addition, the concept of 'cousin' does not exist in most African languages, where an extended family is the norm. The distance implied in the notion of 'cousin' makes the speaker of this utterance uncomfortable, hence the deliberate postmodifiction of the word 'cousin' to bring it closer to home. This to my mind is justification enough for the extra detail in the utterance, and justification enough for the deliberate nonobservance of Grice's maxim.

The argument can be extended to cover utterances 6 and 7 where 'small mother' is an aunt younger that your mother, while a 'big father' would be an uncle older than your father. Such expressions are very common in Africa, where the terms 'aunt' and 'uncle' are considered rather distant. This point is supported by the kinship system in Tshivenda where all aunts and uncles are mothers and fathers respectively with those older than your biological mother and father have the suffix 'big' (muhulu) while those younger have the suffixes 'mane' or 'nene'. Logically then, children of your small/big aunties and uncles (cousins) are your 'brothers' and 'sister' hence the rationale behind utterance 5 .

Still on the issue of 'extraneous' information or the breaking of the maxim of quantity, let us examine utterances 8 and 9:

8) She is a lady teacher.

9) She is a lady principal.

Strict observance of the maxim declares 'lady' in these utterances redundant hence their inclusion would need some justification. In other words, the sex of 'the teacher' and 'the principal' can be deduced from the initial pronoun 'she'. When I asked the speaker of this utterance the rational behind the inclusion of the word 'lady', the explanation was quite straight forward. Formerly most teachers and principals were male, therefore utterances in which the gender of the teacher was not marked, as in:

\section{0) The teacher or principal praised the class.}

The assumption was that reference was being made to the male species. My next question then is that, if the same situation no longer exists, in fact the opposite may be closer to the truth, why has this construction remained? It has remained because it is an indication of the empowerment that women have undergone, they have managed to break into a formerly male bastille, an achievement reflected in the construction of the utterance. Can one, therefore, not argue that the statement has provided more than just enough background information for the correct understanding of the utterance? Are the utterances not observing all the four maxims, quality (the information is true), quantity (only enough information has been provided), relevance and manner (can not be accused of being obscure? So from the speaker's understanding, he/she has been very meticulous in the construction of the utterance. So, even though the hearer could still 
ask for a justification the necessity for this extra information is debateable. Therefore, a statement which started of as questionable after an analysis is shown to have observed the maxims.

\section{1) He is a popular somebody.}

The word 'somebody' is both an indefinite and a compound pronoun. As such it cannot be premodified by an adjective as in the expressions *'a tall somebody', *'a nice somewhere'. Such pronouns can, however, be post-modified as in the expression, 'somebody tall' and 'somewhere nice' which are more usual. The first syntactic problem, therefore, is the positioning of the adjective 'popular' before the pronoun.

The word 'somebody' usually implies that one is not fully aware of the particulars of that person and would prefer to use the less definite term. Semantic non-differentiation, under which this utterance would fall, may also be said to flout Grice's (1989) conversation principle of manner avoid obscurity of expression. A similar accusation can be levelled against utterance 12 below:

12) You are somehow.

This is an expression one hears when a Tshivenda speaker is describing somebody who has behaved in some unexpected or unorthodox manner. Usually the context of the situation will supply the semantic value of the word 'somehow'. 'Somehow' is a general, all-embracing term, with negative connotations intended to describe some unspecified misbehaviour which the speaker frowns upon. Non-South African hearers will experience some difficulties as they attempt to fathom the characteristics of this person and hence can declare the utterance as having failed to adhere to the maxim of quantity: make your contribution as informative as is necessary for the understanding of the current exchange. For any interchange, for which there is an association of doubt, would be breaking one of the maxims. Let us go back to the speaker and work out her/his intention. The speaker, presumably, cannot quite come out with a classifying term for the individual's behaviour. Now the questions to ask are: Is the speaker unable to be specific in her description because she does not have the accurate word in her linguistic bank or because the person's behaviour is not describable? If it is the former (i.e. lack of appropriate word) then Grice's maxims of quantity and manner have been broken. However, if it is the latter (i.e. indescribable behaviour) then no maxim has been broken: the utterance captures the general uncertainty that surrounds the person's behaviour. For the speaker the person is enigmatic and the best way to get this across is to use this non-specific, all-embracing descriptor. The speaker felt that the other synonyms to 'somehow', for example, 'mysterious', 'confusing', 'unreadable' will not capture exactly what she/he wants to say.

\section{CONCLUSION}

An examination of the maxims as applied in the above analysis indicates that they are very general and open to debate and even open to criticisms of subjectivity and obviousness. Nevertheless, conversation maxims when used in ethnographic analysis provide illuminating insight into the creation of meaning among most L2 users and in contexts as those described by the New Englishes. Most of these utterances have been analysed within very limited sociolinguistic parameters, which naturally has a bearing on the analysis and the results. What 
these utterances demonstrate, however, is that they are the preferred ways and mode of making meaning in specialised contexts, for example, within specific L2 cultural contexts.

This whole exercise has also shed light on the notion that it is the hearer's prerogative to identify unusualness or markedness of an utterance. In other words, if as the language philosopher, Austin says (1962) intention or meaning of an utterance rests with the producer, then may it not be assumed that these expressions are the result of very deliberate selection processes by the speakers? In that case adverse classification and misinterpretation of these utterances is rather an indictment of the hearer. Here individual producers are demonstrating their strategic competence. Strategic competence refers to the ability of individuals to manoeuvre themselves successfully in any linguistic situation they find themselves in. In other words, the level of competence attributed to speakers depends on their creativity, flexibility, reasoning and adaptability, all of which, these expressions illustrate.

What these samples show is the complex mental deliberations which go into the creation of meaning in a language other than the speaker's first language. They also show that judgement or evaluation of an utterance, whether a second language speaker is involved or not, need not rest with the hearer alone. It is in any case a complex matter. Before an utterance can be evaluated, a hearer needs to use a variety of objective linguistic processes, limited not only to the surface lexical items, their arrangement and their literal meaning, but also the maxims that a speaker has observed during linguistic interactions. New Englishes make similar demands.

New Englishes, having been developed by their users and their societies for their own needs and understanding, have a strong self-identification value for the users. They are comfortable with these forms which help them to project their own sense of reality, values, concerns and they help them to participate in a world which otherwise might be closed to them. They compel recognition of who and what they are, exactly what these samples are about.

\section{REFERENCES}

AUSTIN, JL. 1962. How to do things with words. London: OUP.

BACH, K \& R HARNISH.1979. Linguistic communication and speech acts. Cambridge: Mass.: MIT Press.

BAMGBOSE, A, A BANJO \& A THOMAS (Eds). 1995. New Englishes: A West African perspective. Lawrenceville, New Jersey: Africa World Press.

BOKAMBA, E. 1992. The Africanization of English. In Kachru, B (Ed.), The other tongue: English across cultures. $2^{\text {nd }}$ Edition. Chicago: University of Illinois Press. 125-147

BROWN, G \& G YULE. 1983. Discourse Analysis. Cambridge: Cambridge University Press.

CHOMSKY, N. 1957. Syntactic structures. The Hague: Mouton.

GREEN, G. 1989. Pragmatics and natural language understanding. Hillsdale, New Jersey: Lawrence Erlbaum Associates. 
GRICE, HP. 1975. Logic and Conversation. In Cole P \& JL Morgan (ed.), Syntax and semantics, Vol 3: Speech Acts. New York: Academic Press.41-58.

HALLIDAY, M. 1978. Language as social semiotic: The social interpretation of language and meaning. London: Edward Arnold.

HERSKOVITS, A. 1997. Context and Language. http://boggie.cs.unitn.it/eecs-97/Discussion/ Archives/0010.html [7 March 2002]

KACHRU, B. 1992. Models for non-native Englishes In Kachru, B (ed.), The other tongue: English across cultures. $2^{\text {nd }}$ Edition. Chicago: University of Illinois Press.48-74.

KEMPSON, R. 1975. Presupposition and the delimitation of Semantics. Cambridge: Cambridge University Press.

LEECH, G. 1983. Principles of Pragmatics. London: Longman

LEVINSON, S. 1989. Pragmatics. Cambridge: Cambridge University Press.

LEVINSON, S. 2000. Presumptive meaning: The theory of generalized conversation implicature. Cambridge, Mass.: MIT Press.

MEY, J. 1993. Pragmatics: An introduction. Oxford: Blackwell.

MONTAGUE, R. 1968. Pragmatics. Reprinted in Thomason, RH (Ed.), Formal Philosophy. 1974. New Haven: Yale University Press. 95-118.

MORRIS, C. 1938. Writings on the general theory of signs. New York: Prentice Hall.

PLATT, J, H WEBER \& ML HO. 1984. The New Englishes. Routledge \& Kegan Paul: London.

SEARLE, JR. 1969. Speech acts: An essay in the philosophy of language. Cambridge: Cambridge University Press.

SPERBER, D. 1995. How do we communicate? In Brockman, J \& K Matson (Eds), How things are: A science toolkit for the mind. New York: Morrow.191-199.

SPERBER, D \& D WILSON. 1986. Relevance: Communication and cognition. Mass.: Harvard University Press.

THOMAS, J. 1995. Meaning in interaction: An introduction to Pragmatics. Addison Wesley

YULE, G. 1996. Pragmatics. Oxford: Oxford University Press.

\section{BIOGRAPHIC NOTE}

Phyllis Kaburise is at the English Department of the University of Venda. Her research interest is in pragmatic use of language and Speech Act theory. Email: 1kaburise@univen.co.za 